\title{
Networking
}

\section{Urgent health care networks}

\begin{abstract}
Geoffrey Meads Health Services and Sciences Research Units, Southampton and Warwick Universities, UK and Valerie Lattimer and Abigail Burgess Health Services Research Unit, Southampton University, Southampton, UK
\end{abstract}

\section{Background}

Across the United Kingdom (UK) over the past 15 years, service and research networks in urgent health care have grown in parallel. For urgent health care services there has been a steady and sustained expansion in the range of services available since the numerical restriction on General Practice (GP) Out-of-Hours was lifted in 1994. Beginning with the advent of GP Cooperatives, this has continued with the increased involvement of other health professionals in urgent care, especially out of hours, and the development of new roles and ways of working. The provision of primary care treatment centres has extended this trend. This arguably reflects a policy shift in primary health care towards the centralisation of service strategy and provision as sites variously referred to as 'treatment centres', 'urgent care centres' and 'primary care emergency centres' are deliberately designed to complement centrally promoted NHS walk-in centres and minor injuries units.

At the same time, the scope of the research in urgent-access primary care has grown from its original narrow focus on the effectiveness of medical services to include a much broader spectrum of professional contributions and knowledge, and a stronger focus on the experiences and preferences of service users. This research now covers, for example, management studies, nurseled assessments, operational modelling and health economists' evaluations (eg, Lattimer et al., 2000;

Address for correspondence: Professor Geoffrey Meads, Institute of Health Sciences Research, Medical School, University of Warwick, CV4 7AL, UK. Email: g.d.meads@ warwick.ac.uk

C 2008 Cambridge University Press
Brailsford et al., 2004; Gerard et al., 2004; Scott et al., 2004). For both urgent health care service and research developments, accordingly, the basic networking tenet for extended primary health care has applied: organised horizontal activity is more effective than hierarchic approaches when the issues to be addressed are complex and the delivery systems fragmented (Warner and Gould, 2007).

The parallel development of service and research networks in urgent health care has not been interdependent, but has been mutually supportive. Indeed, on both fronts it has raised the status of urgent health care to that of a single specialist subject. On the one hand, night-time calls, patient transport, accidents, minor casualty referrals, on-line contacts and emergencies have all been brought together as the object of a discrete commissioning function in the majority of NHS Primary Care Trusts in England, in which there is a new emphasis on prevention and systems-wide perspectives. On the other hand, urgent health care research has moved from being the domain of a few interested individual General Medical Practitioner (GMP) researchers to be the target of multi-disciplinary tenders that no longer depend on a single source but draw on expertise from across a series of academic sites. Recognising that patients receive their care through the wider NHS workforce, the Centre for Service Delivery and Organisation (SDO) research programme on workforce issues is funding twelve studies, with most involving partnerships between different universities. These are addressing aspects of the organisation, recruitment, retention, training and development needs of the NHS workforce. 


\section{Current developments}

One of these studies is being undertaken by a research network connecting primary health care researchers at five British universities: Aberdeen, Bristol, Glasgow, Southampton and Warwick. The research objective is to identify and describe changes in the urgent health care workforce and the impact of these on health systems performance, especially in relation to the patient experience and staff practices. The fact that the senior collaborators for this programme come from each of the universities represents a further strengthening in the relationships of this particular network, which began to form a decade ago through initial communications at the level of reciprocal advisory group memberships and expert witness contributions. The profile of publications over this period has reflected this change, moving from relatively small-scale reports (eg, Moore, 1997) to major collaborative national projects and findings (eg, Lattimer et al., 2004). The current study sees the specialist expertise of its different network members pooled in contributions to a multi-site case study methodology. For example, nurse triage and systems design are lead topics for the Southampton researchers, while the literature review is led by the Scottish researchers building on their previous work in this field (Heaney et al., 2004), and the technological and organisational changes are assessed by those with relevant research backgrounds from Warwick (Dale et al., 2003) and Bristol (Salisbury and Munro, 2003). All the academic contributors come together to ensure that there is a common framework for data capture and analysis, and to share fieldwork resources.

This growing appreciation of the way in which networks can operate in research has paved the way for a more sensitive appreciation of how the emergent networks in urgent health care are developing. From an initial survey of 28 Strategic Health Authorities in England and six Local Health Boards in Scotland, eight case study locations were selected for in-depth examination regarding the scope and scale of their workforce innovations. Phase 1 of the research included observation, frontline staff and corporate management interviews, the conceptual mapping of patient pathways, documentary analysis and Local Reference Group meetings and workshops to explore future scenarios. This phase has now been completed and Phase 2 is under way. This is examining the patient experience through questionnaires and interviews based on a sample frame that covers six common conditions. Phase 1 has so far highlighted the significant extent to which the different types of service network affect the way in which central policies for urgent health care are implemented, as well as the future opportunities for incorporating changes in urgent care within practice-based commissioning.

At this stage, six months prior to the completion of the final report, a provisional assessment of the eight case studies separates them into four network types. In each case the critical decisionmaking about urgent health care arrangements can be traced to a prevailing pattern of largely lateral relationships across the boundaries of individual organisational units. The four types of network may be characterised as essentially professional, executive, commercial or administrative. The case study sites are evenly divided between each type.

In the professional type the prevailing and most influential network is that of inter-GP relationships. In this model, stable GPs seem to have the confidence of both the community and commissioners and changes in urgent health care are being led from conventional surgery settings by individual GMPs in Primary Care Centres. In these the doctors themselves, for example, undertake the bulk of triage functions and strongly outnumber Emergency Care Practitioners. We found such professional networks operating in parts of the South West of England.

The GP/ECP ratio is reversed in one of the case study sites where the relationships between senior managers holds sway. In this South of England executive network, there is a long history of the corporate leadership from the statutory agencies exercising comprehensive systems-wide control. For urgent health care now this is translated into powerful multi-agency commissioning boards, and the large-scale call centre developments utilise major capital and technological investment through a regional ambulance service to cater to multi-agency health and social care contacts and referrals. By contrast, the professional network type relies on systems of data collection overwhelmingly geared up for the requirements of General Medical Services.

Primary Health Care Research \& Development 2008; 9: 109-112 
The third network is novel and evident in some outer London areas. Its commercial features stem from a market orientation that includes both private sector providers of urgent health care services with NHS Primary Care Trusts and clusters of GPs and nursing practice units also exploring ways of moving to a more autonomous business format, with at least quasi-independent sector status. For such a shift there is encouragement from key figures in the network with access to political and financial goodwill. The principle of collaborative advantage (Huxham, 1996) applies to this commercial network type, which appears to lead to more hybrid and diverse innovations in urgent health care. These include, for example, a mixture of specialist on call clinics and telephone consultation facilities at different venues with different opening times.

Such a service model is at the opposite end of a spectrum to the much more standardised version of urgent health care that is to be found when a public administrative network prevails. In this case the most powerful horizontal relationships are between politicians and officials. This appears to be the present situation in the new devolved bureaucracy of Scotland where the large majority of patient referrals have to pass through NHS24 (the health information service for the people of Scotland). The contrast with the commercial network type is illustrated by the different profile of primary care first contact responses. In the administrative type there seems to be a restricted capacity for contributions to urgent health care from locally sited practitioners, managers, professionals and external agencies.

In the final part of the study, Local Reference Groups will be asked to comment on the emerging characterisations and consider the extent to which these best describe their own systems. They will be invited to comment on the systems maps showing the different patient pathways, from contact to treatment, associated with the four types of service model and derived from the data of the case study sites themselves. The typology will then also be compared with other data on emergency and urgent care networks, including those from parallel research, which has highlighted the significance of networks, with distinct managerial and geographic features, for the separate commissioning and provider functions (Turner et al., 2007).

\section{Future implications}

An awareness of the alternative types of network that prevail in urgent health care, and the cultural context to which each belongs, can help to shape effectively future policy processes designed to extend primary health care. A reliance on traditional models of institutional or incremental health policy implementation (John, 1998; Meads, 2006) now seems inappropriate because of their implicit assumption of vertical relationships. More participative and decentralised approaches may be more effective in harnessing the energies contained within the different prevailing patterns of relationships in urgent health care, and in other primary care service sectors as well. However, in looking to promote such approaches through, for example, practice-based commissioning, a note of caution must be sounded. So far all the influential networks identified have been firmly providercentred and -directed. Given this self-interest, there is an important future challenge to be tackled if the new concept of primary care-based commissioning for community health improvement is to be converted into a relational reality.

\section{Declaration}

The authors have no competing interests and would like to acknowledge the contribution of the whole inter-university research team.

\section{References}

Brailsford, S., Lattimer, V., Tararas, P. and Turnbull, J. 2004: Emergency and on-demand health care: modelling a large complex system. Journal of the Operational Research Society 55, 34-42.

Dale, J., Higgins, J., Williams, S., Foster, T., Snooks, H., Crouch, R., Hartley-Sharpe, C., Glucksmann, E., Hooper, R. and George, S. 2003: Computer assisted assessment and advice for 'non-serious' 999 ambulance callers: the potential impact on ambulance despatch. Emergency Medicine Journal 20, 178-83.

Gerard, K., Lattimer, V., Turnbull, J., Smith, H., George, S., Brailsford, S. and Maslin-Prothero, S. 2004: Reviewing emergency care systems 2: measuring patient preferences using a discrete choice experiment. Emergency Medicine Journal 21, 692-97.

Heaney, D., O'Donnell, C., Munro, J., Myles, S. and Ibbotson, T. 2004: An evaluation of the introduction of

Primary Health Care Research \& Development 2008; 9: 109-112 
NHS 24 in Scotland. Glasgow: Scottish Executive Health Department.

Huxham, C. 1996: Collaboration and collaborative advantage. In Huxham, C., editor, Creating collaborative advantage. London: Sage Publications.

John, P. 1998: Analysing public policy. London: Continuum.

Lattimer, V., Sassi, F., George, S., Moore, M., Smith, H., Mullee, M. and Turnbull, J. 2000: A cost analysis of nurse consultation in primary care: evidence from a randomised controlled trial. BMJ 320, 1053-57.

Lattimer, V., Brailsford, S., Turnbull, J., Tamaras, P., Smith, H. and George, S. 2004: Reviewing emergency care systems. 1: insights from dynamic modelling. Emergency Medicine Journal 21, 685-91.

Meads, G. 2006: Primary care in the 21st century. Oxford: Radcliffe Publishing.
Moore, M. 1997: South Wiltshire Out Of hours Project (SWOOP). Group nurse telephone triage in out of hours primary care: a pilot study. BMJ 314, 198-99.

Salisbury, C. and Munro, J. 2003: Walk-in centres in primary care: a review of the international literature. British Journal of General Practice 53, 53-59.

Scott, A., Simeons, S., Heaney, D., O'Donnell, C., Thomson, H., Moffat, K., Ross, S. and Drummond, N. 2004: What does GP out of hours health care cost? An analysis of different models of out of hours care in Scotland. Scottish Medical Journal 49, 61-66.

Turner, J., Nicholl, J. and O'Cathain, A. 2007: A preliminary study of emergency and urgent care networks. London: Department of Health.

Warner, M. and Gould, J. 2007: Give health networks a real chance! Primary Health Care Research and Development 8, 101-104. 